\title{
Beyond the Basics: Access and Equity in the Expansion of Post-Compulsory Schooling in Vietnam
}

\author{
Caine Rolleston ${ }^{1}$ and Padmini lyer ${ }^{2}$
}

\author{
${ }^{1}$ Institute of Education, University College London, United Kingdom. \\ ${ }^{2}$ REAL Centre, Faculty of Education, University of Cambridge, United Kingdom
}

\begin{abstract}
Human capital development, including the expansion and improvement of schooling, has played a crucial role in Vietnam's strong and relatively inclusive economic growth in recent years. Universal access to primary and lower secondary education have been achieved, but progression to upper secondary remains, for the most part, rationed by entrance examinations and the payment of fees. Both supply and access have improved strongly at upper secondary level since the 1990s, in line with rising demand for higher skilled school-leavers. However, it is less clear whether access to upper secondary schooling, and its wider social and economic benefits, is provided equitably. In this paper we employ a unique longitudinal dataset to examine the patterns of both access and attainment in upper secondary education in Vietnam. We consider their implications for equitable educational progression and the extent to which, in light of these patterns, the system can be described as meritocratic.
\end{abstract}

Keywords: access; equity; secondary education; post-compulsory education; Vietnam

\section{Post-compulsory education in Vietnam and 'moving up the value chain'}

Notwithstanding debates around other aspects of the Vietnamese education system, there can be little doubt that the country's policies have been successful in ensuring universal access and strong basic skills development by the end of compulsory education. Education in Vietnam has received much attention since the country's stellar performance in the Programme for International Student Assessment (PISA) in 2012 and again in 2015. The country's 15-year-olds were ranked $17^{\text {th }}$ in maths (2012) and $8^{\text {th }}$ in science (2015), performance levels which are exceptional by comparison with other participating low and middle-income countries (Bodewig 2013; Parandekar \& Sedmik 2016; Glewwe et al 2017). Vietnam's high performing school system is particularly impressive in light of recent trends in other developing countries' education systems. While access to schooling has expanded dramatically since the Millennium and a majority of children even in the poorest countries now attend primary school (UNESCO 2013), education systems have typically faced a 'trade-off' between quantity and quality during periods of expansion, often with negative impacts on learning outcomes (Rolleston 2016). Vietnam is an exception to this pattern; by achieving mass enrolment and learning in tandem, the country has apparently avoided a quantity-quality trade-off ${ }^{1}$. Moreover, at least at primary level, disadvantaged students receive relatively equitable access to quality education (World Bank 2011; Rolleston \& Krutikova 2014).

\footnotetext{
${ }^{1}$ The net primary enrolment rate in Vietnam increased from $85.6 \%$ in $1992-3$ to $98.0 \%$ by 2014 , while the net lower secondary enrolment rate also increased over this period from $72.3 \%$ in $1992-3$ to $94.8 \%$ in 2014 . At the same time, nationally representative data on learning outcomes at Grade 5 indicate significant improvements in both maths and Vietnamese language skills between 2001 and 2007 (Dang \& Glewwe 2018).
} 
However, while education is compulsory at primary (Grades 1-5) and lower secondary (Grades 6-9) levels in Vietnam, upper secondary schooling (Grades 10-12) remains 'voluntary'. Upper secondary schools typically employ their own entrance examinations and are able to charge a wide range of fees (Nguyen \& Nguyen 2007; World Bank 2014)2. Accordingly, costs are shared between education authorities and households, although core costs such as teachers' salaries are largely met from public funds. Nonetheless, access to upper secondary education has increased dramatically over the past 20 years, from only $27.2 \%$ in 1992-93 to 72.4\% in 2014 (Dang \& Glewwe 2018). This trend is testament to increasing demand for education, linked in part to rapid economic growth and to rising levels of education among parents, as well as other factors such as expansion in supply as a result of large-scale school construction, primarily by the government but also including growth in private schools. As Dang \& Glewwe (2018) have noted, the rise in upper secondary enrolment amounts to a significant change from a relatively elite system to a much more accessible and prima facie more equitable system. There are still considerable variations in the quality and quantity of upper secondary education accessed by children of differing home backgrounds. This is partly linked to the costs of private tuition, which is widespread and serves to prepare students for school entrance examinations. Based on analysis of Vietnam Household Living Standards Survey (VHLSS) data, Dang \& Rogers (2016) find that Vietnamese households in the top wealth quintile spend 15 times more on private tuition than households in the poorest wealth quintile.

In terms of costs directly linked to schools, differential fee levels between schools and regions (which in part reflect affordability constraints) may be considered supportive of equity to some extent. For example, fees are reduced or waived for ethnic minorities in isolated areas. This approach is consistent with the Vietnamese principle of 'socialisation' (xã hội hóa), which encourages the sharing of responsibility (including financial responsibility) for the provision of social services between communities, enterprises and government, while the extent of cost-sharing is at least in part conditional on ability to pay (Ta \& Duong 2013). Although controversial, especially for those who believe the costs of education should be met entirely from public funds, in principle and if applied optimally, this approach may serve to harness private demand and funds for education within the public system, thereby increasing the total envelope of resource, while safeguarding equity and without excluding the most disadvantaged students.

In Vietnam, as elsewhere, upper secondary schooling serves as a gateway to access to higher education and in turn to some of the highest 'returns to education'. Upper secondary and university graduates arguably also have access to the most prestigious and rewarding labour market opportunities. Returns to university education among wage workers in Vietnam (relative to primary school leavers) rose to $80 \%$ in 2008, while upper secondary graduates in wage work could expect a return of $30 \%$ (World Bank 2014). Moreover, strong demand for secondary and higher education graduates has remained robust during Vietnam's recent years of relative economic slowdown, particularly in the urban private sector, while demand for less educated workers has been declining (World Bank 2014). Robust demand for skilled workers in the country is linked to a shift in employment patterns, in turn linked to an upward move along the 'value-chain' of production, which has been a clear objective of national economic policy. Economic policy with respect to human capital development emphasises the need to 'skill up' the country's young people for changing employment patterns in a context of intensifying global competition (Le Thuc \& Nguyen 2014), not least in light of opportunities presented by rising costs of production in neighbouring China. Widening access to upper secondary education is arguably crucial in pursuit of this aim, and is consequently an area of growing policy

\footnotetext{
2 In the Young Lives upper secondary school survey (2016-17), the mean annual school fees in sites across five provinces was 2.5 million VND (108 USD), ranging from 0 VND in two Lao Cai schools to 9.6 million VND (414 USD) in one Hung Yen school.
} 
interest in the country (World Bank 2014; London 2010). While gross enrolment rates in upper secondary education are relatively high in Vietnam compared to other Southeast Asian economies, they fall short of enrolment rates in more developed East Asian countries such as the Republic of Korea, with Vietnam's current upper secondary enrolment rate being comparable to Korea's in the 1980s (World Bank 2014: 95).

Vietnam's Education Sector Strategic Development Plan (2011-2020) aims to ensure that $80 \%$ of Vietnamese young people within the relevant age group complete upper secondary education by 2020 (Asian Development Bank 2012). The target of majority rather than universal access does not suggest a logic which construes upper secondary schooling as a fundamental right, at least in the short term, but perhaps an instrumental logic driven by a need to ensure sufficient supply of upper secondary school graduates. Assuming that demand for places exceeds supply, access must therefore be 'rationed', in turn rationing access to labour market opportunities which require upper secondary education or higher. Conditional on limited access, from an equity perspective what matters is the extent to which such rationing is 'fair'.

In order to investigate equity of access to and attainment in post-basic education in Vietnam, we employ rich longitudinal household and school survey data from Young Lives, an international study of childhood poverty, to examine the extent to which access and attainment are explained by 'merit' (considered further below) rather than by factors such as home advantage. It is important to note that the Young Lives study is not nationally representative; the analysis presented in this paper reflect patterns of in/equity in selected sites from five out of 60 provinces in Vietnam. Nonetheless, the longitudinal nature of the Young Lives household and school survey datasets provide a unique opportunity to analyse trends of educational access and learning outcomes over time. Using the Young Lives household dataset, we start by examining the predictors of access to Grade 10 (i.e. the transition from lower to upper secondary school). Using the Young Lives school survey dataset, we then examine the predictors of learning outcomes in Grade 10 for students who do gain access to upper secondary school. In light of Vietnam's aim to develop a twenty-first century economy to 'upskill' its workforce, we conclude by considering the equity implications of these patterns of access and attainment at upper secondary level.

The key questions addressed in the paper are as follows:

1. What are the characteristics of children who successfully make the transition to Grade 10?

2. What are the factors that predict learning outcomes in Grade 10 ?

3. What are the patterns of inequality and inequity in access and learning outcomes from primary to upper secondary school?

While we identify key predictors of transition and of learning progress, conditional on important demographic and socio-economic factors, we do not claim to estimate causal relationships directly. Young Lives provides observational data, and educational outcomes are the result of complex causal processes which are not straightforwardly identifiable or separable using survey data alone. Nonetheless, the availability of measures of prior learning in longitudinal data such as Young Lives does help to reduce the extent of confounding between home backgrounds and learning in our analysis when compared to crosssectional studies. Our approach focuses on predictive indicators, since the intention is not to infer causality but rather to draw inferences regarding equity and equality in the prevailing distributions of educational opportunities and outcomes. This is a somewhat more descriptive exercise, although not entirely so; unlike descriptions of patterns of inequality, assessments of equity depend on value judgements concerning which distributions of outcomes are to be preferred. 


\section{Equitable access and progress in upper secondary education}

Without unlimited resources educational progression must be limited, to the extent that the state meets the costs of provision ${ }^{3}$. Consequently, educational policy makers face choices and trade-offs between quantity and quality across the various levels of education, and in relation to the extent and nature of public versus private provision and of 'cost-sharing'. There are therefore important equity implications as access to education shifts from being a universal right at the more basic levels to being governed by merit-based or other allocation mechanisms at higher levels (Crouch and Rolleston 2017: 4). There are further important implications regarding the efficient use of public resources and, ultimately, for the development of a nation's skills, capabilities and productivity.

Analysis of in/equality of access or outcomes between groups essentially requires descriptive techniques to identify and quantify 'gaps'. By contrast, questions of equity concern, among other things, the extent to which such gaps, or other elements of a distribution of an outcome, are 'fair'. Accordingly, addressing questions of equity requires a value judgement about what, in a particular situation, constitutes fairness and cannot be resolved by statistical methods alone. Some definitions of equitable educational access, based in a human rights approach, view exclusion from any level of education as discriminatory (UNESCO 1960). Following such a definition, access to upper secondary education must be available to all if it is to be equitable. On this understanding, equality and equity of access may be considered one and the same. By contrast, 'unequal' access to post-basic levels of education may be considered 'fairer' (Crouch and Rolleston 2017: 4) or more equitable than universal access if, for example, resources are very limited or certain prerequisites are required to benefit from a particular level of education. But in such cases, it is crucial that the 'allocation mechanism' by which students are granted access is a fair one, and not arbitrary or discriminatory.

One conception of fair allocation is a system of merit-based access (Crouch and Rolleston 2017) - although notions of merit clearly vary and also rely on value judgements. Educational access is in practice most commonly limited by geographical access, the affordability of fees and, in the absence of comprehensive information on students, by entry criteria based on prior educational achievement. These entry criteria sometimes also have mechanisms to reflect differences in opportunity or need, such as quotas or forms of positive discrimination. While prior attainment may be considered a function of factors including students' natural ability, effort, home support and education to date, it also provides a measure of a student's 'readiness' for a particular phase of education and of potential to succeed in and benefit from this phase, including relating to mastery of curricula of previous phases. This notion of potential is also important for merit when understood from an efficiency perspective - merit-based allocation may be conceived as allocation of places to those students most likely to make the most progress, to reach the highest levels of attainment or meet some other standard of success. Clearly, however, 'potential' depends on a great many other skills, attitudes and aptitudes, such as motivation, about which schools often have little information. School entrance tests are thus a somewhat imperfect measure of potential and therefore of 'merit', and testing in part confounds potential with previous advantage. In practice, however, upper secondary schools

\footnotetext{
${ }^{3}$ There are two main forms of private or 'non-public' education in Vietnam; private schools (those with private owners) and people-founded schools (those owned by social or economic organisations). Following Vietnam's Education Law (2005), the government provides a degree of financial support to enable non-public schools to implement state policies (Lieu 2011). Non-public provision at upper secondary level is considerably higher than at primary and lower secondary level; $27.1 \%$ of all upper secondary students were enrolled in non-public schools in $2007-8$, compared to $6.0 \%$ of students enrolled in non-public primary and lower secondary schools. However, public provision remains the preferred option for all but the most advantaged students, conditional on their ability to meet the entry requirements (Lieu 2011).
} 
in Vietnam mostly do employ entrance tests as a primary method of allocating places. And while imperfect, the approach may in some sense be considered fairer than the arbitrariness of geography, which in many contexts is key to determining educational access, or indeed when compared to allocation based on parents' ability to pay fees, often the primary determinant of access to quality education in many other contexts, such as in India (see Rolleston \& Moore 2018).

Nonetheless, in spite of strong access gains, existing national data for Vietnam indicate that there are currently significant equity and equality issues with regard to access to upper secondary level. For example, only 50\% of ethnic minority children progressed to Grade 10 in 2014 compared to $79 \%$ of ethnic majority (Kinh/Hoa) children (Dang \& Glewwe 2018). Moreover, although average attainment at age 15 is undoubtedly high and several attempts have been made to 'unravel the secret' of Vietnam's success in delivering strong cognitive skills following the 2012 PISA results (Bodewig 2013; Parandekar \& Sedmik 2016; Glewwe et al 2017), it has been shown that results overstate performance somewhat, in part because they fail to represent the achievement of disadvantaged students who typically do not make the transition to upper secondary school. Glewwe et al (2017) show that, owing to selective progression, the PISA sample is comprised of relatively advantaged and high-performing students enrolled in Grade 10, which raises some doubts for the interpretation of PISA results as nationally representative of 15-year-olds' skill levels. To date, little evidence is available on those 15 -year-olds who do not progress to Grade 10 and hence are not eligible to participate in PISA.

In addition to being restricted by selection based on examinations, the costs of upper secondary education, including opportunity costs, do influence household decisions relating to participation in schooling. Moreover, decisions may be affected by other supply-side issues including physical access to schools and school quality. On the demand side, influences include family income and educational preferences, among many others. Schooling decisions may be considered as part of a household's overall welfare maximisation or long-term utility strategy and may accordingly be analysed within the cost-benefit analysis framework of Becker's household production function (Becker 1964). This framework conceptualises family investment decisions in education as driven by the long-term net benefits of such investments, when compared to alternatives and subject to family budget constraints. We employ a simplified model based on this framework to examine the determination of enrolment in Grade 10. Concerning the outcomes of education, we employ a simple 'education production function' model. Among the most important outcomes of educational processes are individual students' subject knowledge and cognitive skills. These outputs may be considered the result of educational 'production processes' which serve to combine school-level inputs (e.g. school infrastructure, teachers, curricula etc.), household-level inputs (wealth, parental education) along with individual characteristics (gender, ethnicity) to 'produce' educational outcomes. The education production function provides a simple model of the relationships between these inputs and outcomes, which has played a key role in informing policymakers concerning the determinants of educational achievement, and concerning the importance of particular inputs into the education 'production process', while results from studies employing the model do not provide for obvious policy prescriptions, especially with respect to school-level inputs (Hanushek 1989).

\section{The Young Lives survey and methods}

Young Lives is a longitudinal study of childhood poverty in Ethiopia, India, Peru, and Vietnam. It has followed a total of 12,000 children, divided into two age cohorts, over the course of 15 years; an 'Older Cohort' born in 1994-95, and a 'Younger Cohort' born in 2001-02. In all four countries, a sentinel-site sampling design is employed, comprising 20 purposively selected sites chosen to represent national diversity, but with a pro- 
poor bias. At the site level, children in both birth cohorts were selected randomly in 2001 (2,000 Younger and 1,000 Older Cohort children in each country) so that the data are representative of the birth cohort in each site.

The 20 Young Lives sites in Vietnam are clustered in five provinces: Lao Cai, Hung Yen, Da Nang, Phu Yen and Ben Tre ${ }^{4}$. Each province contains four sites, and each site is formed of one or two communes, totalling 36 communes within 14 districts. Data have been collected from the households of the index children every 3-4 years from 2002-2015, while school-level data collection began in 2011-12 at the schools of the Younger Cohort children who were then enrolled in Grade 5. A second round of school-level data collection took place in 2016-17, at all upper secondary schools in the 14 Young Lives districts. This sampling approach was adopted in order to ensure a high chance of including students who participated in the previous Grade 5 survey as well as those in the Young Lives Younger Cohort. The 2016-17 school survey was conducted in Grade 10, as this was the grade in which the majority of Younger Cohort children were expected to be enrolled.

The Vietnam primary school survey (2011-12) was conducted in 56 schools (or 92 school sites when satellite sites are considered separately) in the 20 Young Lives sentinel sites, and included 3,284 Grade 5 students (1,138 of whom were Young Lives Younger Cohort children). The Vietnam secondary school survey (2016-17) was conducted in 52 schools in the 14 Young Lives districts, with 8,740 students (including 307 Young Lives Younger Cohort children and 469 of their peers from the Grade 5 survey). A more detailed discussion of the sampling and survey design of the primary and secondary school surveys can be found in Rolleston et al (2013) and lyer et al (2017) respectively.

In order to address the question of access to Grade 10, we analyse five rounds of household data collected from the 2,000 Younger Cohort children between 2002 and 2016 (section 4.1). We statistically compare the characteristics of Younger Cohort children who were enrolled in Grade 10 in 2016-17 with those who were eligible to be enrolled in the same year, but were no longer in school. We then use regression analysis, employing a dichotomous outcome (probit) model, to examine the predictors of the probability of enrolment in Grade 10.

Subsequently, in order to examine learning outcomes in Grade 10 (4.2; 4.3), we analyse school survey data from a sub-sample of Younger Cohort children and their peers who participated in both the primary school and secondary school surveys - a total of 776 children. We examine the predictive effects of these students' background characteristics, including their prior attainment (in Grade 5) and primary school quality ('valueadded' at Grade 5), on their attainment in maths at the beginning of Grade 10. We first use a simple linear regression model, and then introduce 'district fixed effects' so that results only compare students with their peers within their district. See Appendices 1 and 2 for summary statistics of variables included in the analysis.

The value-added approach we follow is a simple extension to the basic education production function which introduces a measure of prior attainment (a lagged test-score variable) to account for the contribution of all relevant prior educational inputs (at home and school) whose effects are reflected in a student's attainment at the time of the test. The inclusion of the lagged test score means that the effects of other predictors in the value-added model may be interpreted as conditional on prior attainment, i.e. as being the effects of those predictor variables in the period since the earlier test was conducted. This approach is especially useful when compared to including only contemporaneous measures of achievement when it is important to understand the predictive effects of inputs to educational attainment during particular time periods. A full

\footnotetext{
${ }^{4}$ See Rolleston et al (2013) for a detailed description of the Young Lives sites in Vietnam.
} 
discussion of the value-added framework is provided in Todd and Wolpin (2003). Equation (1) below describes the general framework in simple terms, where T represents a test score of pupil $\mathrm{i}$ at time $\mathrm{t}, \mathrm{X}$ is a vector of child characteristics and $\eta$ an individual error term. The framework may be extended to include school/teacher characteristics or school/teacher 'fixed effects'. When employing school value-added measures as a predictor variable (Grade 5 school value-added in the Grade 10 attainment model), these values are the 'school fixed effects' extracted from a pupil-level regression model which employs Grade 5 maths attainment as the outcome and beginning of Grade 5 tests scores as a predictor variable. Analysis of Grade 5 value-added is reported in in Rolleston et al (2013).

$$
T_{i, t}=\alpha T_{i, t-1}+\gamma X_{i}+\eta_{i}
$$

\section{Findings}

\subsection{Which children make the transition to Grade 10?}

In this section, we analyse five rounds of data collected at the household-level from 2,000 Younger Cohort children between 2002 and 2016 in order to consider the predictors of transition to Grade 10.

In Vietnam, children are expected to enrol in Grade 1 in the calendar year they turn six years old, so that Younger Cohort children born in 2001 would normally have enrolled in Grade 1 in 2007 and, assuming correct age-for-grade progression ${ }^{5}$, would have enrolled in Grade 10 in 2016. Of the 1,551 Younger Cohort children born in 2001 (i.e., those eligible to enrol in Grade 10), 64.9\% were in fact enrolled in Grade 10, while $8.8 \%$ were enrolled in other grades, and $19.3 \%$ were no longer in school. The enrolment figure is somewhat lower than the national estimate of $72.4 \%$, which is likely to reflect the pro-poor selection of sites in the Young Lives sample. Around half of the Younger Cohort children (52.3\%) as a whole were enrolled in Grade 10 in 2016-17, with 20.2\% enrolled in Grade 9, and 17.6\% not enrolled in school (Table 1).

Table 1: Younger Cohort school enrolment, 2016-17 6

\begin{tabular}{ccccccccc}
\hline $\begin{array}{c}\text { School enrolment, } \\
\text { 2016-17 }\end{array}$ & \multicolumn{2}{c}{$\begin{array}{c}\text { Eligible for Grade 10 } \\
\text { (born in 2001) }\end{array}$} & \multicolumn{2}{c}{$\begin{array}{c}\text { Not eligible for Grade 10 } \\
\text { (born in 2002) }\end{array}$} & No information & \multicolumn{2}{c}{ Total } \\
\hline No. & $\%$ & No. & $\%$ & No. & $\%$ & No. & $\%$ \\
\hline Not in school & 300 & 19.3 & 45 & 11.3 & 1 & 5.6 & 346 & 17.6 \\
Grade 8 & 8 & 0.5 & 9 & 2.3 & 0 & 0 & 17 & 0.9 \\
Grade 9 & 104 & 6.7 & 293 & 73.6 & 1 & 5.6 & 398 & 20.2 \\
Grade 10 & 1006 & 64.9 & 21 & 5.3 & 4 & 16.6 & 1031 & 52.3 \\
Grade 11 & 24 & 1.5 & 1 & 0.2 & 0 & 0.0 & 25 & 1.4 \\
No information & 109 & 7.0 & 29 & 7.3 & 16 & 88.9 & 154 & 7.1 \\
Total & 1551 & 100 & 398 & 100 & 22 & 100 & 1971 & 100 \\
\hline
\end{tabular}

\footnotetext{
${ }^{5}$ The most recent figures for Vietnam reveal very low levels of grade repetition at primary level $(1.0 \%$ in 2013$)$ and lower secondary level (1.2\% in 2013) (MOET 2015).

6 Includes attrition, non-response, refusal.

7 Includes attrition, non-response, refusal.
} 
In order to understand more about the differences between those who do and do not make the transition to Grade 10, we compare the Younger Cohort children in Grade 10 in 2016 ( $n=1,031)$ with the out-of-school Younger Cohort children who were eligible to enrol in Grade 10 in the same year $(n=300)$, reporting mean differences using a t-test (see Table 2). The figures reveal significant differences between the two groups in terms of household wealth (with children in Grade 10 from wealthier households on average). We compare performance in maths between the two groups on a standardised test administered to sampled children when they were 12 years old in 2013 (Round 4 of the Young Lives household survey) ${ }^{8}$. This also reveals significant differences between the two groups, with those in Grade 10 scoring higher on average than those who are no longer enrolled in school, by a margin of more than three quarters of a standard deviation. This large difference in earlier maths performance may initially suggest that progression is strongly performancelinked. However, children from more advantaged backgrounds are likely to have benefited from better 'opportunities to learn', and accordingly this finding is not sufficient to support a conclusion that progression is equitable. One might expect a relatively small gap in performance in a system whereby progression into upper secondary school was determined exclusively by income or 'ability to pay', rather than by academic performance.

Nonetheless, there are significant differences in the proportions of children who progress to Grade 10 when comparing across more and less advantaged social groups, as reported in Table 3. More than four-fifths of eligible ethnic majority (Kinh) children were enrolled in Grade 10 at the time of the survey, compared to just under half of all ethnic minority children ${ }^{9}$, results which are similar to those of Dang \& Glewwe (2018) using nationally representative data. A sizeable gap (of more than eight percentage points) is found in terms of the proportion of girls compared to boys enrolled in Grade 10. The gap in the proportions of children enrolled in urban compared to rural areas is twice as large as the gender gap, at more than 16 percentage points. The largest gap among these selected indicators is found when comparing children by level of caregivers' education. Almost $90 \%$ of children whose main caregiver had six or more years of education (i.e. lower secondary education or higher) were in Grade 10 , compared to less than $60 \%$ of those whose main caregiver had five or fewer years of education (i.e. primary education or lower).

Table 2: Differences between Younger Cohort children in Grade 10 and out of school, 2016

\begin{tabular}{lccc}
\hline & In Grade 10 & Out of school & Sig. \\
\hline Wealth Index, 2013 & 0.64 & 0.55 & $* * *$ \\
Maths Test Score, 2013 & 525 & 447 & $* * *$ \\
\hline
\end{tabular}

t-test significance: $* * * p<0.01, * * p<0.05, * p<0.1$.

\footnotetext{
${ }^{8}$ Raw scores on the maths test were transformed to a common scale, using a two-parameter item-response theory (IRT) model to produce estimates of children's latent ability or performance trait $(\Theta)$, which takes account of item difficulty and discrimination between students. The tests have been scaled to have a mean of 500 and standard deviation of 100.

${ }^{9} 85 \%$ of the Younger Cohort sample are from ethnic majority (Kinh) backgrounds. Of the remaining 15\%, the largest ethnic minority group represented is $\mathrm{H}^{\prime}$ mong (5.5\%), with a smaller proportion of children from Dao (1.8\%), Tay (1.7\%), Nung (1.5\%) and $\mathrm{Ba} \mathrm{Na}(0.3 \%)$ backgrounds.
} 
Table 3: Differences between Younger Cohort groups progressing to Grade 10, 2016

\begin{tabular}{|c|c|c|c|c|c|c|c|c|c|c|c|c|}
\hline & $\begin{array}{c}\text { Boys } \\
\text { (\%) }\end{array}$ & $\begin{array}{c}\text { Girls } \\
\text { (\%) }\end{array}$ & Sig. & $\begin{array}{l}\text { Ethnic } \\
\text { minority } \\
(\%)\end{array}$ & $\begin{array}{l}\text { Ethnic } \\
\text { majority } \\
(\%)\end{array}$ & Sig. & $\begin{array}{c}\text { Urban } \\
(\%)\end{array}$ & $\begin{array}{c}\text { Rural } \\
(\%)\end{array}$ & Sig. & $\begin{array}{c}\text { Caregiver's } \\
\text { education: } \\
0-5 \text { years } \\
(\%)\end{array}$ & $\begin{array}{c}\text { Caregiver's } \\
\text { education: } \\
6 \text { or more } \\
\text { years } \\
(\%)\end{array}$ & Sig. \\
\hline In Grade 10 & 73.4 & 81.6 & $* * *$ & 48.9 & 80.8 & $* * *$ & 89.8 & 73.5 & $* * *$ & 58.2 & 87.5 & $* * *$ \\
\hline
\end{tabular}

t-test significance: ${ }^{* * *} p<0.01, * * p<0.05, * p<0.1$

These indicators clearly represent forms of advantage or disadvantage that are closely linked, overlapping and mutually reinforcing. We therefore proceed to model these explanatory factors simultaneously as predictors of the probability of progressing to Grade 10 in a regression framework. We employ a dichotomous outcome (probit) model, taking the value 1 for being enrolled in Grade 10 and 0 for being out of school. We report marginal effects on the probability of enrolment (see Table 4) at the mean for all predictor variables. We control for site-level clustering with respect to the outcome and explanatory variables (using site fixed effects), so that results serve to compare children with their peers within each Young Lives site, limiting the potential for confounding between student/home characteristics and geographic, economic and demographic factors at the site level.

We estimate two models: in the first model, we include gender, ethnicity, caregiver's education and household wealth in 2013 as predictors of enrolment. In the second model, we add an indicator of prior maths performance, again using standardised scores from the maths test administered to sampled children in 2013.

Table 4: Probability of being enrolled in Grade 10 in 2016

\begin{tabular}{lcc}
\hline VARIABLES & $\begin{array}{c}(1) \\
\text { Grade } 10 \text { enrolment } \\
\text { without prior test scores }\end{array}$ & $\begin{array}{c}(2) \\
\text { Grade } 10 \text { enrolment } \\
\text { with prior test scores }\end{array}$ \\
\hline Female & $0.108^{* * *}$ & $0.0938^{* * *}$ \\
& $(0.0227)$ & $(0.0214)$ \\
Ethnic minority & $-0.109^{* *}$ & -0.0330 \\
& $(0.0498)$ & $(0.0470)$ \\
Main caregiver's education & $0.176^{* * *}$ & $0.137^{* * *}$ \\
(6 or more years) & $(0.0303)$ & $(0.0291)$ \\
& & \\
Wealth index, 2013 & $0.658^{* * *}$ & $0.443^{* * *}$ \\
& $(0.116)$ & $(0.109)$ \\
Maths score, 2013 & - & $0.00115^{* * *}$ \\
& - & $(0.000132)$ \\
Site fixed effects & YES & 1,257 \\
Observations & 1,298 & \\
\hline
\end{tabular}

Controls included for site-level (fixed) effects. Standard errors in parentheses: ${ }^{* *} \mathrm{p}<0.01,{ }^{* *} \mathrm{p}<0.05, * \mathrm{p}<0.1$ 
Without controlling for prior test score (column 1 in Table 4), ethnic minority children are significantly less likely to progress to Grade 10 . However, when taking account of prior maths performance, ethnic minority status is not a significant predictor of progression. This suggests that children from ethnic minority backgrounds may not be additionally disadvantaged in terms of making the transition to Grade 10, beyond the significant disadvantage that is reflected in their lower test scores at age 12 (a gap of 0.87 standard deviations - see Appendix 3). Lower test scores nonetheless do reduce the likelihood of accessing upper secondary school significantly. In fact, a one standard deviation increase in prior test score is associated with an almost 12 percentage point increase in the probability of progression (column 2 in Table 4). Moreover, lower test scores among ethnic minority and other disadvantaged children are likely to reflect a pattern of historical inequality and inequity (see Appendix 3 for differences in performance according to child characteristics and family background, including ethnicity).

After taking account of maths ability, children whose main caregiver has six or more years of schooling remain significantly more likely to progress to Grade 10 than those whose main caregiver has five or fewer years of education, while children from more advantaged backgrounds (measured by wealth index in 2013) are also more likely to transition to Grade 10, other things being equal. This suggests that the effects of parental education and wealth (plus other child background factors associated with these indicators) continue to exert an influence in the period after the 2013 test was administered. This result is not unexpected since parental education serves as an indicator of educational preferences, and household wealth provides a strong indicator of family 'means'.

Even after controlling for prior performance, girls remain significantly more likely to progress to Grade 10 than boys. While this contradicts expectations that girls might be the 'disadvantaged' group in terms of educational access and progression during adolescence, as found in many other countries (e.g. Vennam et al 2016), it is consistent with nationally representative findings on gender and transition to Grade 10 in Vietnam reported by Dang \& Glewwe (2018). Previous findings from Young Lives have indicated higher expectations that boys enter the labour market once they reach adolescence when compared to girls, so it may be the case that without similar pressures to start earning, girls are more able to progress to higher levels of education at this age (Zharkevich et al 2016).

In Figure 1 below, we examine in indicative terms the overlap in test scores in 2013 between children who entered Grade 10 and those who did not. This shows that children who progressed to Grade 10 scored, on average, more highly than those who are out of school. However, there is also a considerable overlap in the distribution of maths test scores across these two groups, which further emphasises that higher ability alone does not ensure transition to Grade 10. While some students may choose not to progress, this also suggests that some high-ability students may be prevented from making the transition to Grade 10 for other reasons, for example by the costs of upper secondary education. 
Figure 1: Maths test scores (2013) for Younger Cohort children in Grade 10 and out of school

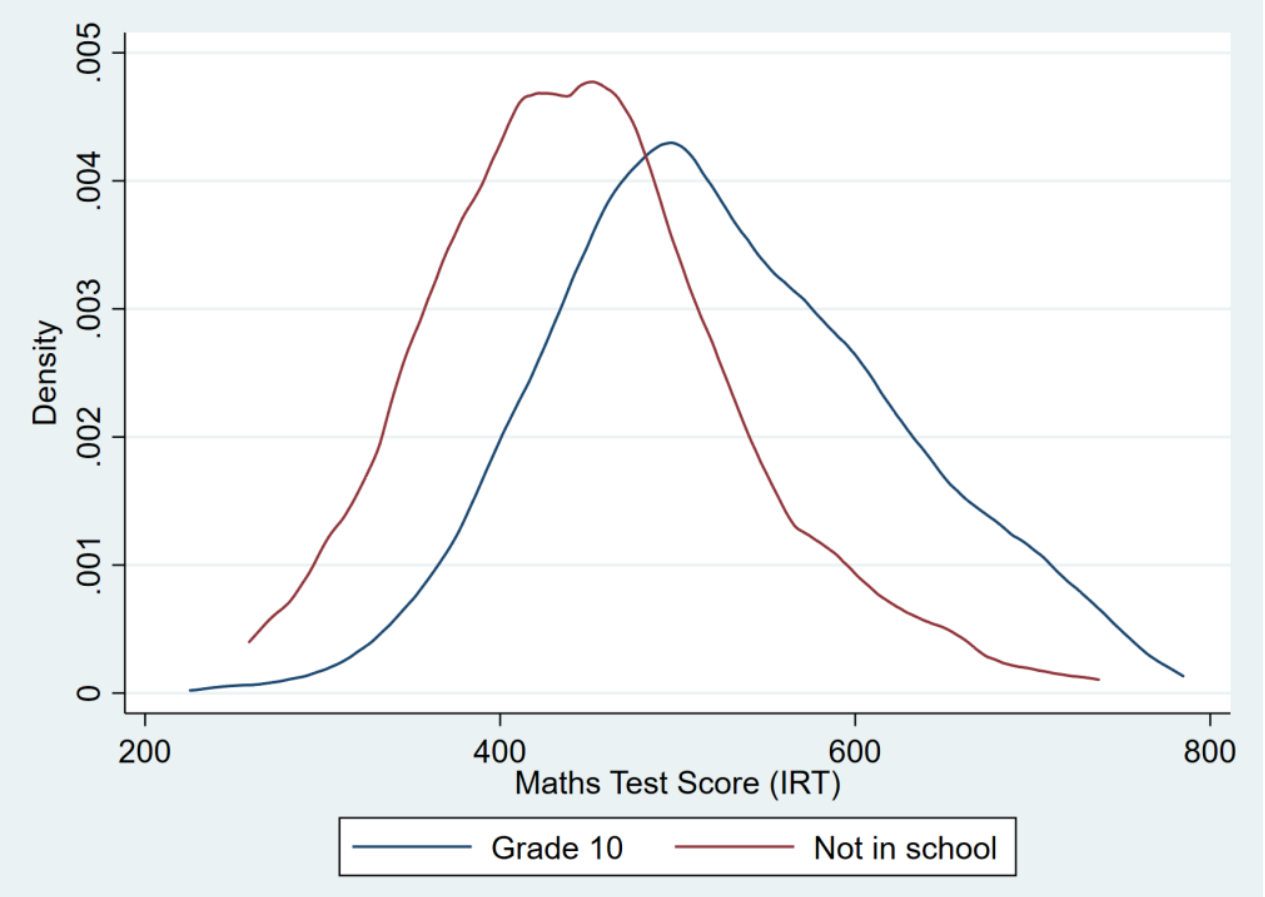

These findings indicate that access to post-basic education in Vietnam is clearly not as equitable as at earlier stages, where access is close to universal. In an equitable system, where access is purely determined by merit, we would not expect wealth or caregiver's education to be a significant predictor of access after controlling for prior performance. Home advantage clearly plays an important role with respect to progression to Grade 10, suggesting that access to upper secondary education is determined by 'unfair inequality' (Crouch \& Rolleston 2017). While efforts are made in some provinces to reduce the required scores for progression (or even to waive the use of entrance exams entirely - lyer et al 2017) in order to encourage disadvantaged children to transition to upper secondary school, these findings suggest that remedial action in earlier years may be required. For example, if disadvantaged students are the lower performers by the end of Grade 9, compensatory mechanisms earlier on in primary and lower secondary school may be needed to ensure that home disadvantage does not limit school performance later on.

\subsection{What are the factors associated with learning outcomes in Grade 10?}

Having examined equity in access to post-basic education in Vietnam, we turn to learning outcomes in the first year of upper secondary education (Grade 10), and examine the extent to which these outcomes are equitable among those who do make it to this stage of education. In order to do this, we focus on a subsample of 776 students (307 of whom are Young Lives Younger Cohort children) who participated in both the Young Lives primary and secondary school surveys, since we have longitudinal data on achievement in school for this group in Grades 5 and 10. We examine the effects of indicators of background characteristics, prior achievement and primary school 'value-added' on achievement in maths at the end of Grade 10. We first use a simple ordinary least squares (OLS) linear regression model, and then employ a district fixed-effects model 
so as to compare students only with their peers within their district (Table 5$)^{10}$. Grade 5 and Grade 10 test scores are presented here as scaled IRT scores, with the mean of each test set to 500 and standard deviation set to 100 for ease of interpretation.

Higher maths test scores at the end of Grade 10 are strongly associated with higher Grade 5 test scores in maths and Vietnamese, indicating that high-performing students at primary level continue, other things being equal, to be high performers in the first year of upper secondary school. Home advantage (measured by household wealth index in Grade 5) and mother's education are associated with better learning outcomes, with wealthier students and those with university-educated mothers performing better at the start of Grade 10 even after taking into account their Grade 5 scores. This suggests a continuing influence of these forms of advantage across the schooling career from Grades 5 to 10, both in terms of learning outcomes and (as discussed above) selection into upper secondary education.

It is important to note that other markers of disadvantage - ethnic minority status, speaking a minority language at home, eating fewer meals, health problems at primary school and grade repetition - are not significant predictors of learning outcomes at the end of Grade 10 in this 'value-added' model ${ }^{11}$. By contrast, these variables were important predictors of achievement in both maths and Vietnamese at Grade 5 when no prior achievement measures were included (see Rolleston et al 2013). One explanation for the apparent reduction in the importance of these variables is that their influence is primarily exerted earlier in the child's school career, and subsequently absorbed in Grade 5 test scores. The sample of students in Grade 10 is also a relatively more advantaged sample than the full sample of students tested in Grade 5, and the influence of more basic socio-economic indicators for this group may be expected to be weaker.

The negative effect of Grade 5 'value-added' on learning outcomes in Grade 10 is initially unexpected; however, rather than suggesting that lower quality primary schooling leads to better performance in Grade 10, this may reflect the fact that the primary schools attended by less advantaged and initially lowerperforming students were found to add more value than those attended by advantaged students (see Rolleston et al 2013). In turn this may reflect test-effects in Grade 5 in the sense that it may be 'easier' to make progress from a lower base on the Grade 5 curriculum, or the fact that where value-added was especially high in Grade 5 due to idiosyncratic factors (such as measurement error) this could be expected to limit measured progress in the period thereafter.

In the OLS model (column 1), students in Ben Tre, Da Nang and especially Hung Yen and Phu Yen perform significantly better than those in Lao Cai (the reference category). Province indicators serve to capture all influences common to students within the provinces, both on the supply (e.g. school quality) and demand sides. Lao Cai is the poorest province in economic terms and also the most geographically remote, so it may be expected that forms of socio-economic advantage common to students in other provinces and unobserved in our model would be reflected in significant province effects when compared to Lao Cai.

\footnotetext{
${ }^{10}$ As discussed above, while the Young Lives sentinel sites are made up of 1-2 communes, sites in the 2016-17 school survey consist of the 14 districts in which Young Lives communes are located.

11 In the OLS model, the following non-significant variables are jointly significant: gender, age, ethnicity, mother's education $(F(5,692), p=0.08)$. We do not find joint significance for non-significant variables in the $F E$ model $(F(9,683)$, $p=0.88)$.
} 
https://doi.org/10.1016/j.ijedudev.2018.09.002

Table 5: Student background characteristics, primary schooling and Grade 10 maths performance

\begin{tabular}{|c|c|c|}
\hline \multirow{2}{*}{ VARIABLES } & (1) & $(2)$ \\
\hline & OLS & Fixed Effects \\
\hline \multirow[t]{2}{*}{ End of Grade 5 maths score } & $0.378 * * *$ & $0.363 * * *$ \\
\hline & $(0.0493)$ & $(0.0495)$ \\
\hline \multirow[t]{2}{*}{ End of Grade 5 Vietnamese score } & $0.126 * * *$ & $0.142 * * *$ \\
\hline & $(0.0423)$ & $(0.0429)$ \\
\hline \multirow[t]{2}{*}{ Grade 5 school value-added } & $-0.275^{* *}$ & $-0.387 * * *$ \\
\hline & $(0.120)$ & $(0.128)$ \\
\hline \multirow[t]{2}{*}{ Female } & -0.571 & -0.395 \\
\hline & (7.169) & (7.133) \\
\hline \multirow[t]{2}{*}{ Age } & -4.242 & -2.116 \\
\hline & $(7.794)$ & $(7.784)$ \\
\hline \multirow[t]{2}{*}{ Ethnic minority } & -13.88 & -16.41 \\
\hline & $(15.84)$ & $(15.84)$ \\
\hline \multirow[t]{2}{*}{ Wealth Index, Grade 5} & $5.239 *$ & $5.131^{*}$ \\
\hline & $(2.679)$ & $(2.687)$ \\
\hline \multirow[t]{2}{*}{ Mother's education = Secondary education } & 15.55 & $16.20^{*}$ \\
\hline & $(9.792)$ & $(9.727)$ \\
\hline \multirow[t]{2}{*}{ Mother's education = Higher education } & 19.44 & $22.16^{*}$ \\
\hline & $(13.32)$ & $(13.26)$ \\
\hline \multirow[t]{2}{*}{ Speaks Vietnamese at home } & 10.29 & 14.58 \\
\hline & $(15.48)$ & $(15.89)$ \\
\hline \multirow[t]{2}{*}{ Number of meals normally eaten per day } & 2.222 & 0.717 \\
\hline & $(9.706)$ & (9.691) \\
\hline \multirow[t]{2}{*}{ Any health problems in Grade 5} & -7.716 & -6.585 \\
\hline & $(8.637)$ & (8.593) \\
\hline \multirow[t]{2}{*}{ Number of books in the home } & 1.055 & 0.681 \\
\hline & $(3.212)$ & $(3.213)$ \\
\hline \multirow[t]{2}{*}{ Own place to study in the home } & 2.365 & 1.942 \\
\hline & $(10.20)$ & $(10.14)$ \\
\hline \multirow[t]{2}{*}{ Repeated at least one school grade } & -14.54 & -13.45 \\
\hline & $(21.35)$ & $(21.34)$ \\
\hline \multirow[t]{2}{*}{ Ben Tre } & $24.67 * *$ & \\
\hline & $(12.15)$ & \\
\hline \multirow[t]{2}{*}{ Da Nang } & $24.69 * *$ & \\
\hline & $(12.40)$ & \\
\hline \multirow[t]{2}{*}{ Hung Yen } & $52.77^{* * *}$ & \\
\hline & $(13.57)$ & \\
\hline \multirow[t]{2}{*}{ Phu Yen } & $39.46 * * *$ & \\
\hline & $(12.26)$ & \\
\hline \multirow[t]{2}{*}{ Constant } & $262.9 * *$ & $252.0 * *$ \\
\hline & $(126.0)$ & $(125.9)$ \\
\hline Observations & 713 & 713 \\
\hline R-squared & 0.258 & 0.234 \\
\hline Number of districts & & 14 \\
\hline Site FE & & Yes \\
\hline
\end{tabular}

Standard errors in parentheses $* * * p<0.01, * * p<0.05, * p<0.1$

Reference categories: Mother's education (Primary education); Province (Lao Cai) 


\subsection{What are the patterns of inequality and inequity in learning outcomes from primary to upper secondary school?}

Making use of maths tests completed by the same sub-sample of 776 students at the beginning and end of Grade 5 and the beginning and end of Grade 10, it is possible to examine how inequalities in maths performance develop over time ${ }^{12}$. Figure 2 illustrates the maths progress made by three groups (terciles) of students, based on a household wealth index taken from the Grade 5 school survey. In Grade 5, there were clear gaps in learning outcomes according to wealth at the beginning of the year, with students in the top wealth tercile scoring 61 points ( 0.61 standard deviations) higher than students in the bottom wealth tercile, and 40 points higher than students in the middle wealth tercile. However, students in the bottom wealth tercile made higher-than-average learning progress in maths over the course of Grade 5 (40 points, compared to the sample average of 33 points) than those in the middle tercile (36 points) and top tercile (24 points), indicating that the poorest students were able to 'catch up' during the year. In Grade 10, there are similar gaps between the same student groups at the beginning of the year. Interestingly, students in the bottom tercile made similar progress to those in the top tercile in Grade 10 ( 27 and 26 points respectively), and more progress than those in the middle tercile (20 points). Although the learning gap between students in the top and bottom wealth terciles does not narrow in Grade 10 as it did in Grade 5, existing inequalities according to wealth are at least not exacerbated in the first year of upper secondary school.

Figure 2a: Maths progress by wealth tercile, Grade 5

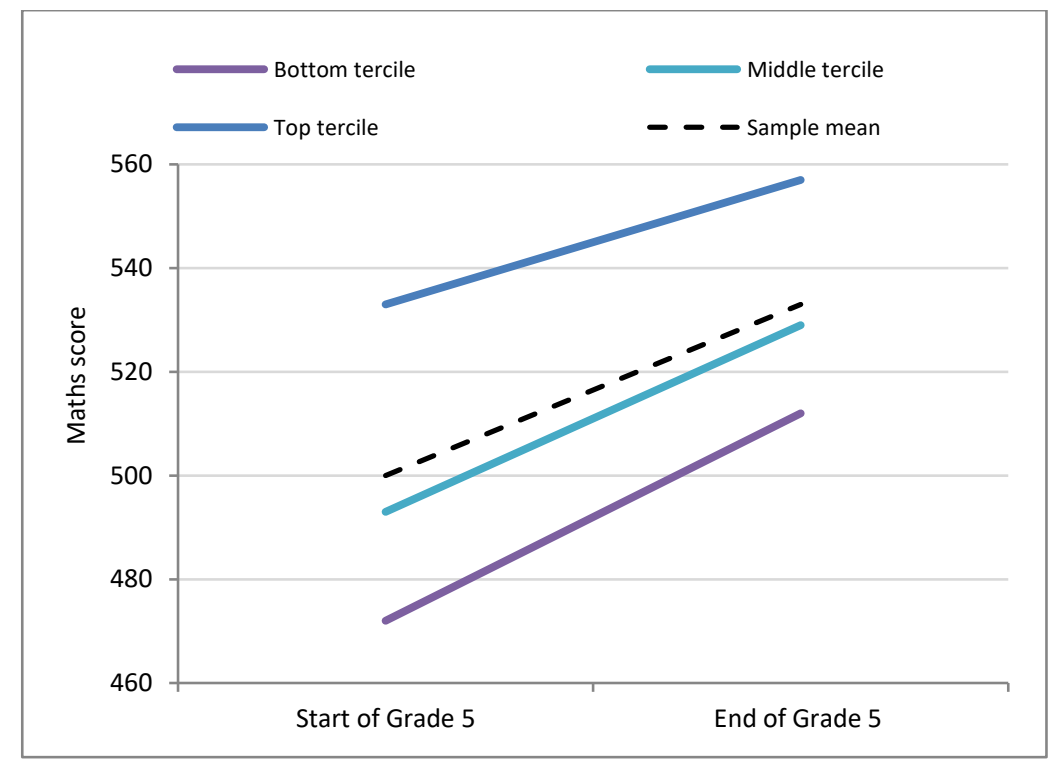

\begin{tabular}{lccc}
\hline & Bottom tercile $(n=233)$ & Middle tercile $(n=286)$ & Top tercile $(n=245)$ \\
\hline Beginning of Grade 5 & 472 & 493 & 533 \\
End of Grade 5 & 512 & 530 & 557 \\
Mean learning gain & $41^{* * *}$ & $37^{* * *}$ & $24^{* * *}$ \\
\hline
\end{tabular}

\footnotetext{
12 The maths tests administered in Grade 5 and Grade 10 included four common items; however, this is not sufficient to link the tests on a common scale. The Grade 5 maths tests and the Grade 10 maths tests were therefore scaled separately, and consequently scores on the two tests are not directly comparable.
} 
Students in the bottom wealth tercile made significantly more progress in Grade 5 (17 points) than students in the top wealth tercile $(p<0.1)$. No other significant differences in progress between wealth terciles found.

Figure 2b: Maths progress by wealth tercile, Grade 10

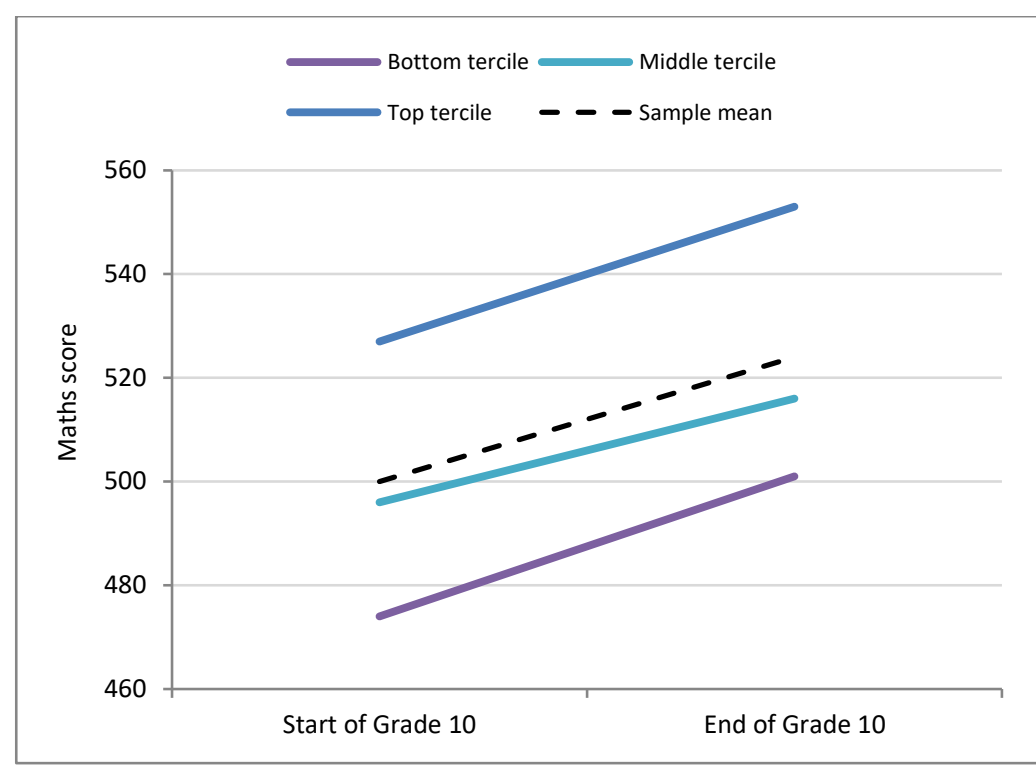

\begin{tabular}{lccc}
\hline & Bottom tercile $(\mathrm{n}=217)$ & Middle tercile $(\mathrm{n}=266)$ & Top tercile $(\mathrm{n}=244)$ \\
\hline Beginning of Grade 10 & 474 & 496 & 527 \\
End of Grade 10 & 501 & 516 & 553 \\
Mean learning gain & $27^{* * *}$ & $19 * * *$ & $26^{* * *}$ \\
\hline
\end{tabular}

No significant differences in Grade 10 progress between wealth terciles found.

However, when looking at learning trajectories of ethnic majority and minority students, it does appear that the gap in learning outcomes between these groups has widened over time (Figure 3). In Grade 5, while there is a considerable gap between ethnic majority and minority students' maths scores at the beginning of the year (66 points), ethnic minority students made almost double the progress that ethnic majority students made over the year (59 and 31 points respectively), which lead to a much narrower gap in learning outcomes by the end of Grade 5 (see also Rolleston et al 2013). By contrast, the learning gap between the same ethnic majority and minority widens over the course of Grade 10, as ethnic minority students made slightly less progress than ethnic majority students (18 and 24 points respectively). 
https://doi.org/10.1016/j.ijedudev.2018.09.002

Figure 3a: Maths progress by ethnic status, Grade 5

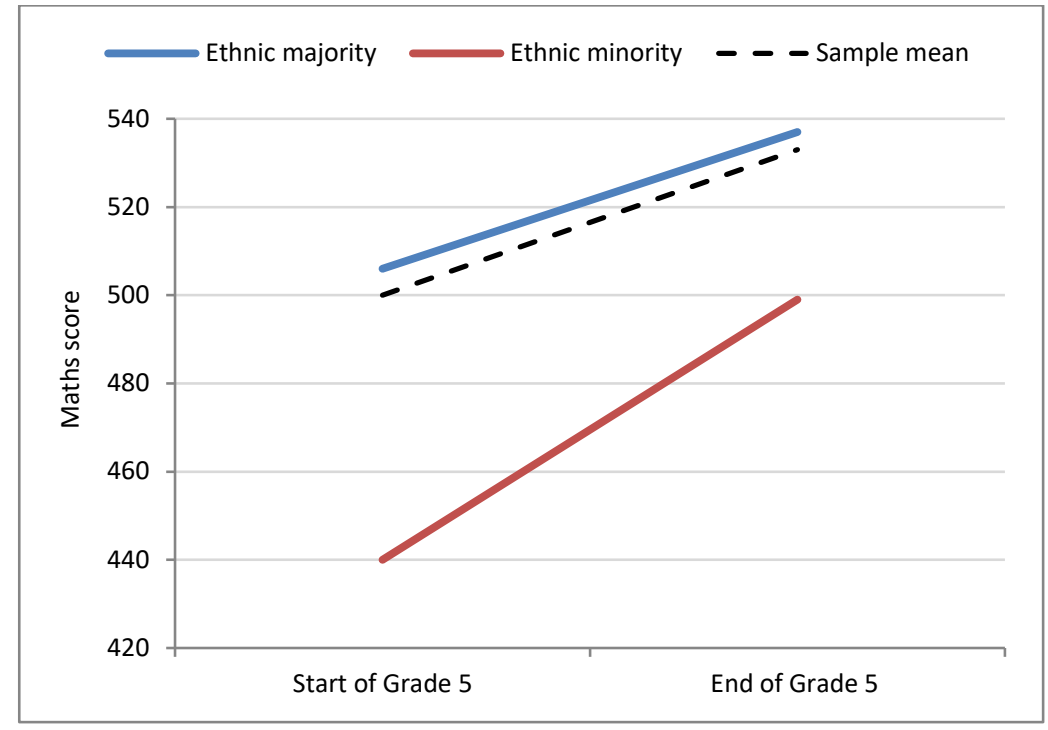

\begin{tabular}{lcc}
\hline & Ethnic minority $(\mathrm{n}=72)$ & Majority Kinh $(\mathrm{n}=692)$ \\
\hline Beginning of Grade 5 & 440 & 506 \\
End of Grade 5 & 449 & 537 \\
Mean learning gain & $58^{* * *}$ & $32^{* * *}$ \\
\hline
\end{tabular}

Ethnic minority students make significantly more progress in Grade 5 (25 points) than majority Kinh students ( $p<0.05)$.

Figure 3b: Maths progress by ethnic status, Grade 10

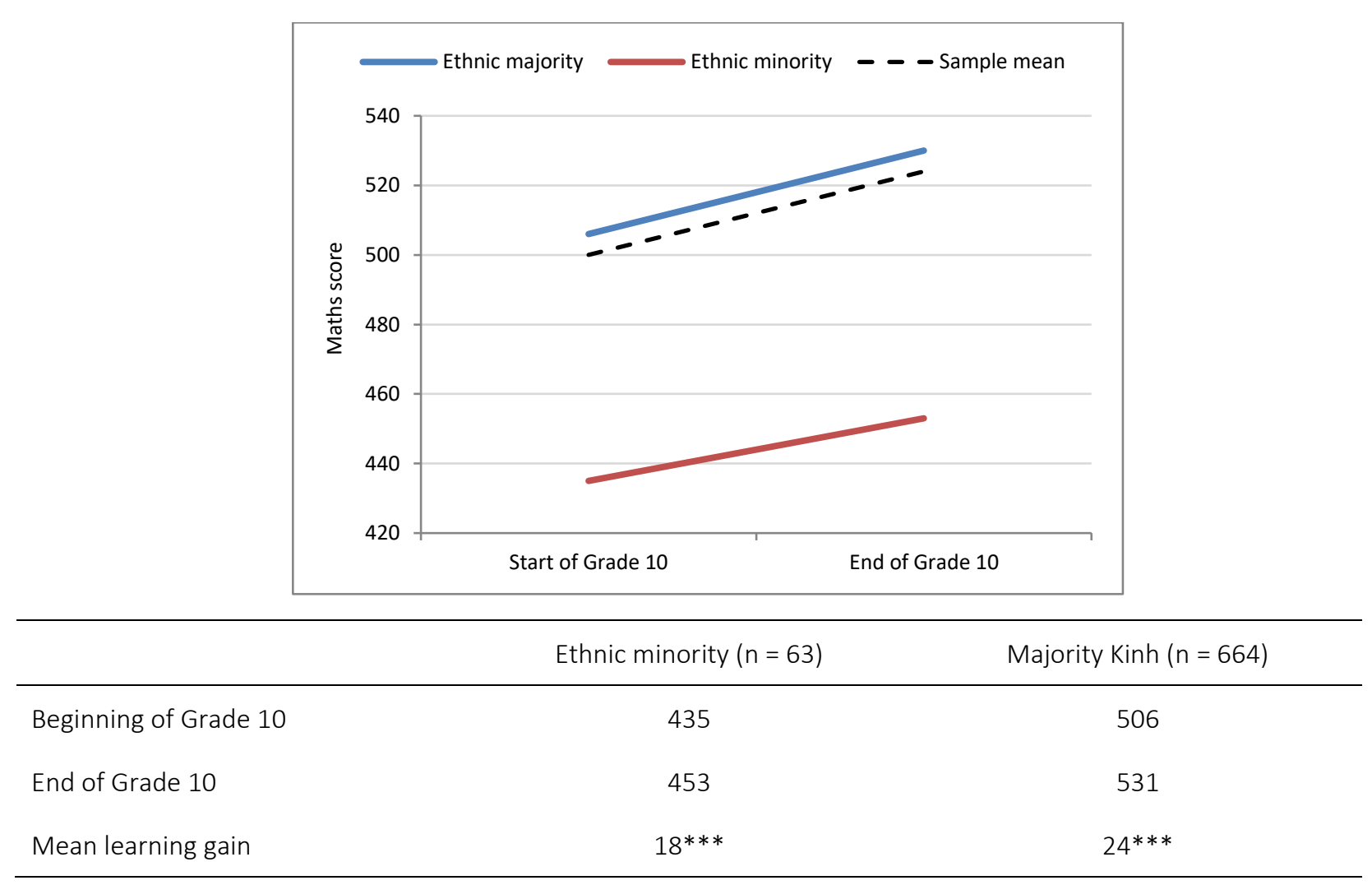

No significant difference in Grade 10 progress between ethnic minority and majority Kinh students found. 
It is hardly unusual to find that students from more advantaged groups are performing better educationally in any context, but there is greater debate about when gaps emerge and develop. While an education system cannot 'correct' all the inequalities of wider society, a system focused on equitable progress will set out to ensure that educational merit or potential is a key determinant of learning outcomes, separated as far as possible from economic circumstances.

Feinstein (2003) provides an example of how the equity of learning trajectories can be examined in this way. In an influential paper using 1970 birth cohort data from the UK on longitudinal measures of cognitive development, Feinstein (2003) examined the learning trajectories of four groups of children: (1) high ability, high socio-economic status; (2) high ability, low socio-economic status; (3) low ability, high socio-economic status; and (4) low ability, low socio-economic status. Between the ages of 22 months and 10 years, Feinstein (2003) reported that children from advantaged backgrounds who scored poorly in early tests had a tendency to 'catch up'. By contrast, children from disadvantaged backgrounds who scored poorly early on were extremely unlikely to catch up, and entry into schooling did not reverse this pattern. As shown in Figure 4 , advantaged children were much more likely to be in the top performance quartile than the lowest by age 10, even if they were in the bottom performance quartile at 22 months (Feinstein 2003).

Figure 4: Average rank of test scores at 22, 42, 60 and 120 months, by socio-economic status of parents and early rank position, British 1970 Cohort (Feinstein 2003: 85)

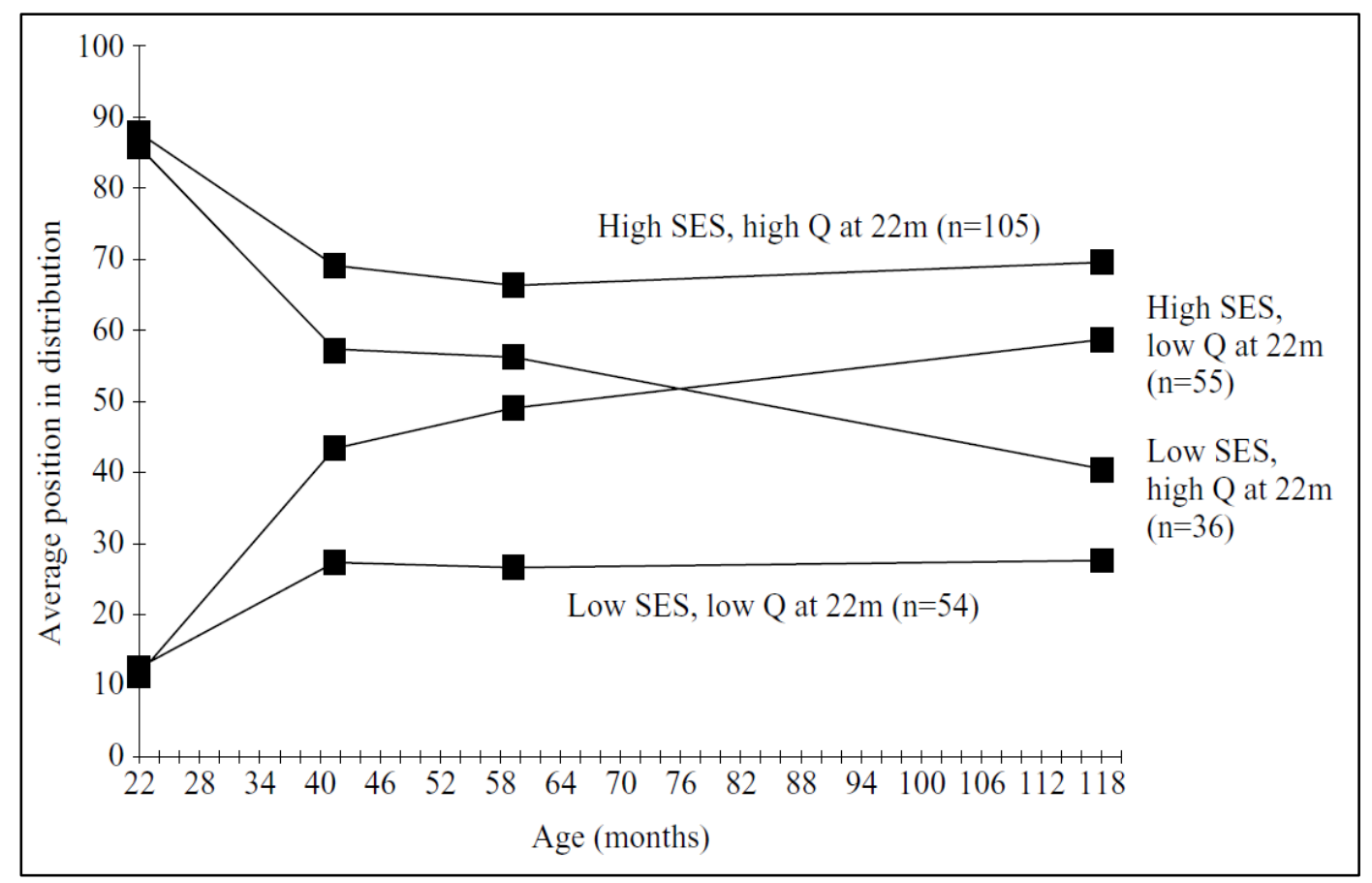

Feinstein's findings, and the claim that his analysis indicated 'the extent to which the formation of human capital is influenced by family background' in the UK (2003: 89), played an important role in shaping government policy of major pre-school educational interventions in the 2000s (Bynner et al 2015). The findings have not been uncontroversial; in particular, Jerrim \& Vignoles (2011) challenged the existence of the 'crossover' as in part an effect of 'regression to the mean' (see also Bynner et al 2015). However, Feinstein's (2003) analysis does provide an example of what an inequitable education system would look like 
- one in which wealthier children outperform poorer children regardless of their initial performance or ability levels.

Using data on learning outcomes at the beginning and end of Grades 5 and 10 from the Young Lives school surveys, when the 776 students who participated in both surveys were approximately 10, 11, 15 and 16 years old respectively, we conduct similar analysis to consider the equity of learning trajectories in the Vietnamese system. We group students by both educational performance and household wealth (as measured at the beginning of Grade 5) into four groups as follows ${ }^{13}$ :

- High-performing, advantaged: top performance tercile, top wealth tercile

- High-performing, disadvantaged: top performance tercile, bottom wealth tercile

- Low-performing, advantaged: bottom performance tercile, top wealth tercile

- Low-performing, disadvantaged: bottom performance tercile, bottom wealth tercile

Figure 5: Average rank of test scores by advantage and performance groups in Vietnam, Grade 5 to Grade 10 $(n=332)^{14}$

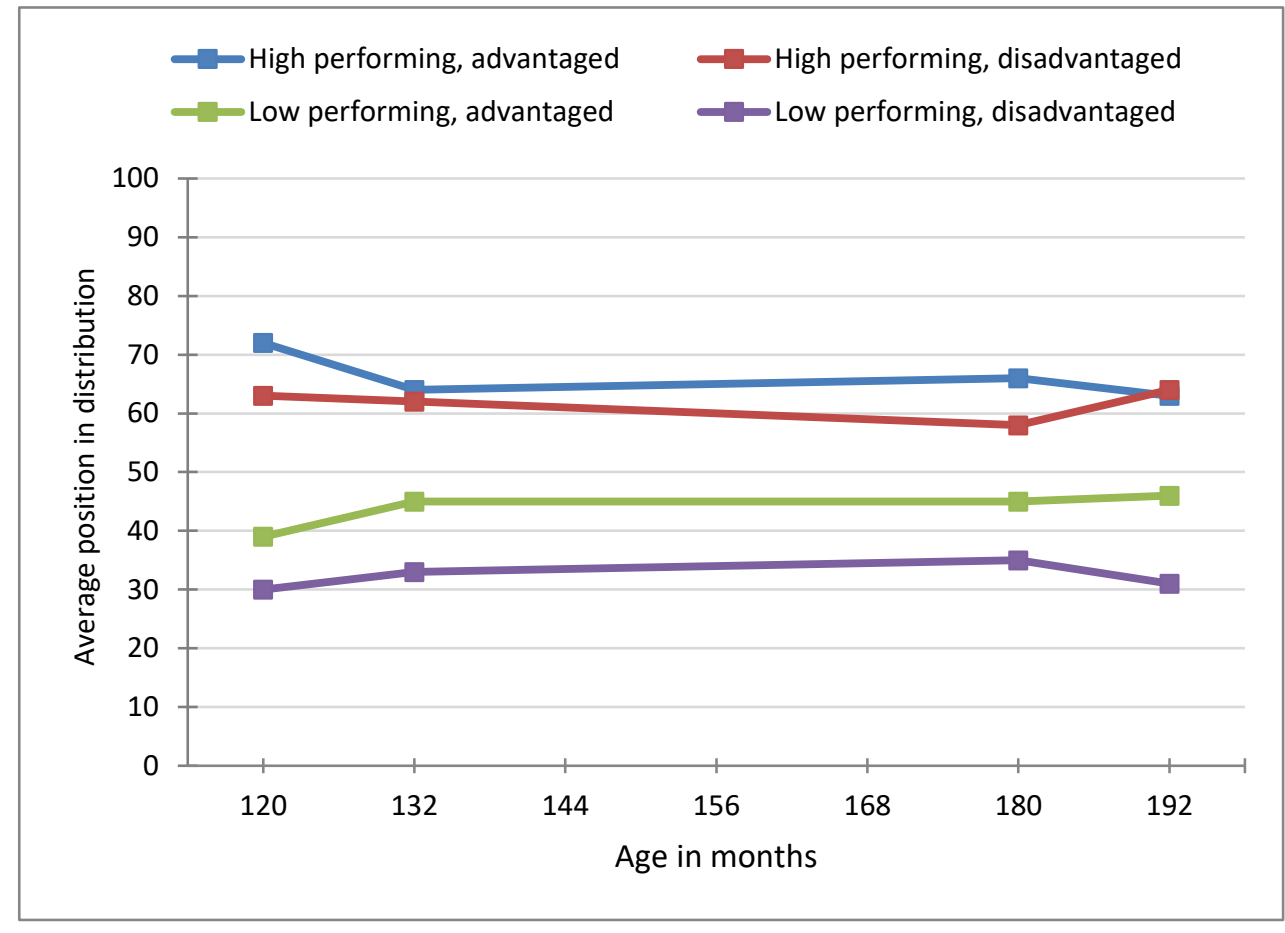

${ }^{13}$ Wealth index in Grade 5 was used as the indicator of household wealth, while 'school performance' is estimated using the part of the student's maths score that is correlated with the Vietnamese score. We follow this approach to mitigate problems of measurement error due to 'guessing' on multiple choice tests and also because using a single test to define a 'high ability' group can lead to a significant proportion of individuals being misclassified - see Jerrim \& Vignoles (2011).

${ }^{14}$ Analysis of variance indicates statistically significant differences in average rank between all groups at each point in time ( $p<0.05$ ), except for the high performing/advantaged and high performing/disadvantaged groups, where analysis of variance indicates no significant differences in average rank at 132, 180 and 192 months. From 120 months to 132 months, analysis of variance indicates a significant difference in the change in rank between the low performing/disadvantaged group and high performing/advantaged group $(p<0.01)$. We find no significant differences between groups from 132 months to 180 months. From 180 months to 192 months, we find a significant difference in the change in rank between high performing/disadvantaged and high performing/advantaged groups $(p<0.05)$. While we have attempted to mitigate the issue of 'regression to the mean', this may be expected to have greatest effect during the first period (due to any misclassification at 120 months linked to remaining measurement error in test scores). 
As shown in Figure 5, low-performing, disadvantaged students in our Vietnam sample do appear to fall behind over time, with the gap increasing between this group and students of comparable performance levels but from more advantaged backgrounds. However, unlike Feinstein's (2003) findings from the UK, lowperforming, advantaged students do not overtake high-performing, disadvantaged students in our Vietnam sample; in fact, high-performing, disadvantaged students appear to 'catch up' with high-performing, advantaged students by the end of Grade 10. The results presented in Figure 5 are evidently not representative of the Vietnamese education system as a whole, and it is important to note that these patterns of academic performance and dis/advantage are based on a sub-set of the 776 students in the Young Lives longitudinal sample ( $n=332$, excluding students in the middle performance and wealth terciles). However, based on these students' performance over time, we might infer the system is relatively equitable - one in which high-performing, disadvantaged students continue to achieve high learning outcomes over time.

\section{Discussion and conclusions}

As one of several Southeast Asian countries seeking to avoid a 'middle-income trap', ensuring equitable access to quality upper secondary education and to higher levels of skills is of increasing importance for Vietnam (Pereira 2016; World Bank 2011). This paper has drawn on longitudinal household and school survey data to answer key questions about access and equity in upper secondary education in Vietnam, namely: (1) the characteristics of children who make the transition to Grade 10; (2) the factors associated with learning outcomes in Grade 10; and (3) the patterns of inequality and inequity in access and learning outcomes from primary to upper secondary school.

There are evidently limitations to the analysis presented in this paper; most importantly, the findings are not nationally representative, but instead reflect patterns of inequality and inequity in selected sites from five provinces in Vietnam. Findings related to ethnic status should also be treated with some caution, since the five ethnic minority groups in the Young Lives sample ( $\mathrm{H}^{\prime}$ mong, Dao, Tay, Nung and $\mathrm{Ba} \mathrm{Na}$ ) are not necessarily representative of ethnic minorities in Vietnam as a whole.

In spite of these limitations, Young Lives school survey data provide a unique opportunity to analyse trends in learning outcomes over time, since they include data collected in the last year of primary school (Grade 5) and the first year of upper secondary school (Grade 10). We find that prior performance is strongly associated with progression to Grade 10, and Grade 10 maths performance is strongly associated with higher maths scores at the end of Grade 5, which indicates somewhat 'meritocratic' progression. Our findings also demonstrate a 'reverse gender gap' in access to upper secondary education - i.e., girls are more likely than boys to progress to Grade 10 . This is consistent with nationally representative findings from Dang \& Glewwe (2018), and may be linked to expectations that adolescent boys participate in the labour market rather than going to school (Zharkevich et al 2016). Conditional on entry to upper secondary school, however, we find no gender gap in attainment in this sample.

Performance in Grade 5 represents both ability and advantage, and it is important that policies concerning progression through education take account not only of realised learning levels but also of potential, adjusted for 'opportunities to learn' which are affected by factors including home background and earlier school quality. Moreover, even when we condition on earlier performance, we find additional effects of household wealth and educational support and preferences (as represented by main caregiver's education) for both progression and achievement. This suggests continuing influences of home advantage across the 
educational life course, leading to persistent inequities. These findings on the importance of wealth and educational preference are consistent with those reported by Dang \& Glewwe (2018), but the importance of student prior performance on transition to upper secondary school in Vietnam has not, to our knowledge, been estimated elsewhere.

Analysis of Young Lives household data indicates substantial inequities in access to upper secondary education. Most obviously, while $81 \%$ of ethnic majority children in the Young Lives Younger Cohort progressed to Grade 10 , only $49 \%$ of ethnic minority children made this transition. These proportions are comparable to those reported nationally (79\% and 50\% respectively - see Dang \& Glewwe 2018), in spite of the pro-poor characteristics of the Young Lives sample. Mitigation of such inequities may require specific policies. While ethnic minority status is not a significant predictor of transition when controls are included, it is clear that 'exclusion' of ethnic minorities operates through indirect mechanisms, most obviously their lower average test scores, lower average household wealth and lower levels of mothers' education.

When examining trends over time, we find that the tendency of ethnic minority students to 'catch up' over the course of Grade 5 (Rolleston et al 2013) is not mirrored in the first year of upper secondary school; the gap between ethnic minority and majority students in fact widens slightly over the course of Grade 10. If this is taken to suggest weaker development of maths skills among ethnic minority students during upper secondary schooling more generally, it can be inferred that this may affect their performance in the highstakes national examination at the end of Grade 12. Since this examination marks a key threshold which rations access to higher education and, ultimately, to highly skilled and well-paid occupations, the longerterm effects of inequitable access may be much more substantial than those we are able to detect with the present data.

While our findings do not point directly towards specific discrimination in the system with regard to ethnic minority students, they do suggest that further compensatory policies to improve access for minorities may be desirable. Equally, our analysis suggests that ethnic majority students from disadvantaged backgrounds would benefit from such policies. Policies of this kind are already in place in some localities, such as the provision of ethnic minority boarding schools in remote areas of Lao Cai province, which are intended to address both supply and demand barriers for the least advantaged students (lyer, Rolleston \& Vu, forthcoming). Nonetheless, further interventions may be required both to ensure disadvantaged students can access upper secondary education based on academic potential (which may require 'positive discrimination' with respect to examination scores used as entry criteria), and that they are not excluded based on ability to pay. The latter issue may require additional policies to ensure fee exemptions, subsidies or conditional cash transfer schemes to offset opportunity costs of schooling in the most disadvantaged areas.

Overall, our findings indicate that there are inequities in access and learning outcomes at upper secondary level in Vietnam, with notable gaps between ethnic minority and majority students in terms of both access and attainment. However, examining learning trajectories over time in Vietnam, high-performing, disadvantaged children continue to achieve high learning outcomes from primary through to upper secondary school. In an education system in which inequities were more entrenched, we might expect wealthier children to outperform poorer children over time regardless of their ability levels (e.g. Feinstein 2003). While the country is not yet at a point of rationing access to higher levels of education on the basis of solely of what might be considered 'fair inequalities', indications of relative equity across the basic and postbasic education systems in Vietnam are an encouraging starting point for the country's ambitions to 'skill up' its young people for a twenty-first century economy. 


\section{Funding}

This work was supported by the UK Department of International Development [grant number: P05126], Irish Aid [grant number: Young Lives], and the Royal Norwegian Embassy, Hanoi [grant number: 8221.SRV-2822 SRV-15/0005].

\section{References}

Asian Development Bank (2012) Vietnam Education and Training Sector Assessment, Strategy and Roadmap. Southeast Asia Department Working Paper. Manila: Asian Development Bank.

Becker, G.S. (1964) Human capital: a theoretical and empirical analysis, with special reference to education. University of Chicago Press, Chicago.

Bodewig, C. (2013) 'What explains Vietnam's stunning performance in PISA 2012?', East Asia \& Pacific on the rise blog, 12 November, http://blogs.worldbank.org/eastasiapacific/what-explains-vietnam-s-stunningperformance-pisa-2012. Accessed 19 October 2015.

Bynner, J., Feinstein, L., Jerrim, J., Vignoles, A., Goldstein, H., French, R., Washbrook, E., Lee, R. \& Lupton R. (2015) 'Social class differences in early cognitive development', Longitudinal and Life Course Studies, 6: 331376.

Crouch, L. \& Rolleston, C. (2017) Raising learning levels: equitable improvement starts with the tail. Research on Improving Systems of Education (RISE) Insight Note. Oxford: RISE Programme.

Dang, H-A. H. \& Glewwe, P. (2018) 'Well begun, but aiming higher: a review of Vietnam's educational trends in the past 20 years and emerging challenges', The Journal of Development Studies 54 (7): 1171-1195,

Dang, H-A. H. \& Rogers, F. H. (2016) 'The decision to invest in child quality over quantity: household size and household investment in education in Vietnam', The World Bank Economic Review 30 (1): 104 - 142.

Feinstein, L. (2013) 'Inequality in the early cognitive development of British children in the 1970 Cohort', Economica 70: $73-97$.

Glewwe, P., Lee, J., Vu, K. \& Dang, H. A. (2017) 'What explains Vietnam's exceptional performance in education relative to other countries? Analysis of the 2012 PISA data'. Paper presented at Research on Improving Systems of Education (RISE) Annual Conference, Washington D.C., 15 June 2017.

Hanushek, E. A. (1989) 'The impact of differential expenditures on school performance', Educational researcher, 18(4), 45-62.

Iyer, P, Azubuike, O. B. \& Rolleston, C. (2017). Young Lives School Survey, 2016-17: Evidence from Vietnam. Oxford: Young Lives.

Jerrim, J. \& Vignoles, A. (2011) The use (and misuse) of statistics in understanding social mobility: regression to the mean and the cognitive development of high ability children from disadvantaged homes. Department of Quantitative Social Science Working Papers No. 11-01. London: UCL Institute of Education.

Le Thuc, D. \& Nguyen, T. (2014) Education and Learning: Round 4 Preliminary Findings from the 2013 Young Lives Survey (Round 4) in Vietnam. Oxford: Young Lives. 
Lieu, T. T. B. (2011) 'Market-oriented education: Private (people-founded) upper secondary schools in Hanoi', in Education in Vietnam, ed. J. London, pp. 132-151. Singapore: Institute of Southeast Asian Studies.

London, J. (2010) 'Globalisation and the governance of education in Vietnam', Asia Pacific Journal of Education 30 (4): pp. 361-379.

Ministry of Education and Training (2015) Vietnam: Education for All 2015 National Review. Hanoi: Ministry of Education and Training.

Nguyen, Q. K. \& Nguyen, Q. C. (2008) 'Education in Vietnam - development history, challenges and solutions', in B. Frediksen \& J-P. Tan (eds.) An African exploration of the East Asian education experience. Washington, D.C.: World Bank, pp. 109-154.

OECD (2013) PISA 2012 results in focus: What 15-year-olds know and what they can do with what they know. Paris: OECD

OECD (2016) PISA 2015: Results in focus. Paris: OECD.

Parandekar, S. D. \& Sedmik, E. K. (2016) Unravelling a secret: Vietnam's outstanding performance on the PISA test. Policy Research Working Paper 7630. Washington, D.C.: World Bank.

Pereira, J. D. (2016) Equity, access and educational quality in three South-Asian countries: the case of Indonesia, Malaysia and Vietnam. Singapore: The HEAD Foundation.

Rolleston, C. (2011) 'Educational access and poverty reduction: the case of Ghana 1991 - 2006. International Journal of Educational Development 31: 338-349.

Rolleston, C. (2016) Escaping a low-level equilibrium of educational quality. RISE Working Paper 16/008. London: DFID.

Rolleston, C. \& James, Z. (2015) 'After access: Divergent learning profiles in Vietnam and India', Prospects 45: $285-303$.

Rolleston, C., James, Z., Pasquier-Doumer, L. \& Thi Minh Tam, T. N. (2013) Making progress: report of the Young Lives School Survey in Vietnam. Working Paper 100. Oxford: Young Lives.

Rolleston, C. \& Krutikova, S. (2014) 'Equalising opportunity? School quality and home disadvantage in Vietnam', Oxford Review of Education 40 (1): 112 - 131.

Rolleston, C., \& Moore, R. (2018) Young Lives School Survey, 2016-17: Value-added Analysis in India. Research Report. Oxford: Young Lives

Ta, V. T. \& Duong, T. V. A. (2013) Socialization policy and access of the rural poor to education in Vietnam. ESP Working Paper Series, No. 51. London: Privatisation in Education Research Initiative (PERI).

Todd, P. E., \& Wolpin, K. I. (2003). 'On the specification and estimation of the production function for cognitive achievement', The Economic Journal, 113(485), F3-F33.

UNESCO (1960) Convention on discrimination in education. Adopted by the General Conference at its eleventh session, Paris, 14 December. Paris: UNESCO.

UNESCO (2013) The global learning crisis: why every child deserves a quality education. Paris: UNESCO.

Vennam, U., Komanduri, A. \& Roest, J. (2016) Gendered trajectories through school, work and marriage in India. Working Paper 156. Oxford: Young Lives. 
World Bank (2011) Implementation Completion and Results Report - Primary Education for Disadvantaged Children project, Vietnam. Washington, D.C.: World Bank.

World Bank (2014) Skilling up Vietnam: Preparing the workforce for a modern market economy. Main report. Hanoi: Vietnam Development Information Centre.

Zharkevich, I., Roest, J. \& Vu Thi Thanh, H. (2016) Gendered trajectories through school, work and marriage in Vietnam. Working Paper 158. Oxford: Young Lives.

\section{Appendix 1}

Summary statistics for variables used in analysis: access to Grade 10 (Younger Cohort sample)

\begin{tabular}{|c|c|c|c|c|c|c|}
\hline VARIABLES & Description & Obs. & Mean & Std. Dev. & Min. & Max. \\
\hline wi4 & Wealth index, 2013 & 1,919 & .6123075 & .1338824 & .0509259 & .9018518 \\
\hline R4mat_theta & Maths score, 2013 & 1,855 & -.0014359 & .9348513 & -2.568651 & 2.662963 \\
\hline sex & Female & 1,970 & .4862944 & .499939 & 0 & 1 \\
\hline ethnic & Ethnic minority & 1,970 & 0.14264 & .3497937 & 0 & 1 \\
\hline careedu_bin & $\begin{array}{l}\text { Main caregiver's education } \\
\text { (6 years or more) }\end{array}$ & 1,949 & .6233966 & .4846584 & 0 & 1 \\
\hline typesite4 & Rural location & 1,843 & 0.806294 & .3953084 & 0 & 1 \\
\hline
\end{tabular}




\section{Appendix 2}

Summary statistics for variables used in analysis: learning outcomes in Grade 10 (Young Lives Grade 5 \& Grade 10 school survey sample)

\begin{tabular}{|c|c|c|c|c|c|c|}
\hline VARIABLES & Description & Obs. & Mean & Std. Dev. & Min. & Max. \\
\hline G5irt_mat2 & End of Grade 5 maths score & 766 & 533.0956 & 96.123 & 261.6255 & 776.3777 \\
\hline G5irt_vn2 & $\begin{array}{l}\text { End of Grade } 5 \text { Vietnamese } \\
\text { score }\end{array}$ & 766 & 525.489 & 100.3692 & 190.0925 & 745.5701 \\
\hline VA_g5 & Grade 5 school value-added & 776 & 7.764048 & 35.13935 & -114.2103 & 103.2559 \\
\hline gender & Student's gender & 776 & .5270619 & .4995891 & 0 & 1 \\
\hline age & Student's age & 776 & 15.24098 & .4514305 & 15 & 18 \\
\hline ethn2 & Ethnic minority & 776 & .0927835 & .2903159 & 0 & 1 \\
\hline wi_g5 & Wealth index (in Grade 5) & 776 & .0361624 & 1.582867 & -6.196282 & 4.589747 \\
\hline healthprob & $\begin{array}{l}\text { Any health problems } \\
\text { (reported in Grade 5) }\end{array}$ & 776 & .2190722 & .4138844 & 0 & 1 \\
\hline studplac & $\begin{array}{l}\text { Own place to study at home } \\
\text { (reported in Grade 5) }\end{array}$ & 772 & .8251295 & .3801025 & 0 & 1 \\
\hline repgrade & $\begin{array}{l}\text { Ever repeated any grades at } \\
\text { school (reported in Grade 5) }\end{array}$ & 775 & .0296774 & .1698054 & 0 & 1 \\
\hline mom_educ2 & Mother's education & 775 & \multicolumn{4}{|c|}{ Takes values $1-3$ for primary to higher education } \\
\hline vthome & $\begin{array}{l}\text { Vietnamese spoken at home } \\
\text { (reported in Grade 5) }\end{array}$ & 774 & \multicolumn{4}{|c|}{ Takes values $0-2$ for never to always } \\
\hline nummeal & $\begin{array}{l}\text { Number of meals eaten per } \\
\text { day (reported in Grade 5) }\end{array}$ & 773 & \multicolumn{4}{|c|}{ Takes values $1-3$ for number of meals } \\
\hline numbook & $\begin{array}{l}\text { Number of books in the home } \\
\text { (reported in Grade 5) }\end{array}$ & 774 & \multicolumn{4}{|c|}{ Takes values $0-3$ for 0 to more than 10 books } \\
\hline province & Province & 776 & \multicolumn{4}{|c|}{ Takes values $1-5$ for each province } \\
\hline
\end{tabular}


https://doi.org/10.1016/j.ijedudev.2018.09.002

\section{Appendix 3}

Maths scores at age 12 (2013) by child characteristics and family background

\begin{tabular}{|c|c|c|c|}
\hline VARIABLES & Mean & Std. Dev. & Freq. \\
\hline \multicolumn{4}{|l|}{ Gender } \\
\hline Boys & 494.83 & 99.91 & 955 \\
\hline Girls & 505.17 & 99.79 & 900 \\
\hline \multicolumn{4}{|l|}{ Ethnic status } \\
\hline Ethnic majority & 511.28 & 95.81 & 1,612 \\
\hline Ethnic minority & 423.97 & 93.73 & 243 \\
\hline \multicolumn{4}{|c|}{ Main caregiver's education } \\
\hline $0-5$ years & 456.35 & 87.21 & 671 \\
\hline 6 or more years & 524.82 & 98.20 & 1,163 \\
\hline \multicolumn{4}{|c|}{ Household wealth, 2013} \\
\hline Top tercile & 534.61 & 100.24 & 555 \\
\hline Middle tercile & 508.27 & 92.05 & 616 \\
\hline Bottom tercile & 458.73 & 95.06 & 571 \\
\hline
\end{tabular}

